\title{
Environmental factors and their impact on the intestinal microbiota: a role for human disease?
}

\author{
Biedermann, Luc ; Rogler, Gerhard
}

\begin{abstract}
The intestinal microbiota and its potential role in human health and disease have come into the focus of interest in recent years. An important prerequisite for the achieved advances with regard to a better characterization of its complex composition and influencing factors is the increasing availability and affordability of culture-independent methods, such as high-throughput sequencing technologies. We discuss some general aspects of the intestinal microbiota. Recent insights into its potential pathogenetic role in the metabolic syndrome and inflammatory bowel disease will also be discussed that imply an impact of smoking status and smoking cessation on intestinal microbial composition.
\end{abstract}

DOI: https://doi.org/10.1159/000342590

Posted at the Zurich Open Repository and Archive, University of Zurich ZORA URL: https://doi.org/10.5167/uzh-76198

Journal Article

Accepted Version

Originally published at:

Biedermann, Luc; Rogler, Gerhard (2012). Environmental factors and their impact on the intestinal microbiota: a role for human disease? Digestive Diseases, 30(Suppl. 3):20-27.

DOI: https://doi.org/10.1159/000342590 


\title{
Environmental factors and their impact on the intestinal microbiota: a role for human disease?
}

\author{
Luc Biedermann, M.D. ${ }^{1}$, Gerhard Rogler M.D., Ph.D. ${ }^{2,3}$
}

\section{Affiliation:}

${ }^{1}$ Division of Gastroenterology and Hepatology, University Hospital Zurich, Zurich, Switzerland,

${ }^{2}$ Zurich Center for Integrative Human Physiology, University of Zurich, Zurich, Switzerland.

\section{Correspondence to:}

Luc Biedermann, M.D.,

Division of Gastroenterology and Hepatology,

University Hospital Zurich,

Rämistrasse 100, 8091 Zurich, Switzerland.

Phone: +41-44-255-3642,

Fax: +41-44-255-9497,

E-mail: luc.biedermann@usz.ch

Conflicts of interest: The author declares no conflicts of interest.

Key words: microbiota; inflammatory bowel disease; ulcerative colitis; smoking, smoking cessation environmental factors 


\section{Abstract:}

The intestinal microbiota and its potential role for human health and disease have come into the focus of interest in recent years. An important prerequisite for the achieved advances in a better characterization of its complex composition and influencing factors is the increasing availability and affordability of culture independent methods, such as high-throughput sequencing technologies. In the following some general aspects of the intestinal microbiota as well as recent insights into its potential pathogenetic role in the metabolic syndrome and inflammatory bowel diseases (IBD) shall be discussed that imply an impact of smoking status and smoking cessation on intestinal microbial composition. 


\section{General Aspects about the Intestinal Microbiota:}

An incredible number of microorganisms colonize the human gut: around 10-100 trillion[1] in an impressively high density of $10^{11}-10^{12}$ organisms per ml of luminal content [2], with Bacteroidetes and Firmicutes as the most abundant (more than 90\%) phyla in humans and mammalians [2-4]. In recent years the human intestinal microbiota has moved increasingly into focus of attention and research by a variety of medical and biological subdisciplines. Its important influence in the development of innate immunity $[5,6]$, regulation of epithelial development or nutrition $[7,8]$ is now well established.

The gut microbiota seems to play an important role in the initiation and perpetuation of intestinal inflammation as evidenced in animal studies with germ free maintained mouse models, where intestinal inflammation did not develop $[9,10]$. Direct evidence for the thesis that intestinal microbes are necessary to initiate and maintain intestinal inflammation in humans was derived with the observation that during diversion of fecal stream no signs of inflammation were apparent in patients with $C D$ with prompt recurrence after restoration of intestinal continuity and fecal stream [11].

Besides the relatively linkage of the gut microbiota and IBD already known for some time, there is accumulating evidence of a role in the pathogenesis in various other disease states, such as irritable bowel syndrome $[12,13]$ as well as obesity and the metabolic syndrome $[14,15]$. Furthermore, a pathogenic role is also suggested in diseases, where a connection to intestinal microbes appears less intuitive, such as Rheumatoid Arthritis [16], multiple sclerosis [17] and even psychiatric or behavior disorders, including autism [18] or alcoholism [19]. 
Although our knowledge on alterations in microbial composition in various disease states has increased in recent years, achievement of several important research goals in the field of the intestinal microbiota still awaits completion:

What is it exactly, that represents a normal gut microbial composition? What are the main factors, influencing the composition - predominantly the environment or genetic factors? What is the impact of global variations in microbial composition - are findings and implications from different studies investigating the gut microbiota in health and disease from different countries comparable? Is there a core gut microbiota?

A characterization of a "normal" microbiota as precise as possible is an essential prerequisite to identify alterations in microbial composition in various disease states. However, the impressive inter-individual $[20,21]$ (and to a lesser degree intra-individual) differences with regard to species composition but also relative abundance of phyla constitute a major obstacle. The debate, whether there is a core gut microbiome - i.e. a certain set of universal microbial organismal lineages that all human individuals share - is still ongoing. For instance, although no single bacterial phylotype could be detected in abundant frequency in all examined mono- and dizygotic twin groups, the existence of a core gut microbiome at the level of shared genes was postulated [22]. However, as the degree of similarity, that revealed to be higher within family members compared to unrelated individuals, did not differ between monozygotic and dizygotic twins in that study, the genetic influence on microbiota composition appears to be weaker than anticipated. Instead, environmental factors, such as nutrition, may early exert a strong influence.

Based on mathematical models, it can be concluded, that there is no shared universal species among all humans in the gut at the $1 \%$-level of abundance. The same is true with 
regard to the microbiota on human hands at a 2\%-level [23]. In this calculation and for several other quantitative and qualitative analyses, species was approximated with a $97 \%$ OTU concordance. This means, that the possibility that we all share bacterial species in our guts at a high level of abundance can be ruled out. And although humans share a group of some ubiquitous phyla, the level of abundance is highly variable between individuals.

If there is not a core set of species - what about a core set of genes? And what is it, that finally counts with regard to intestinal human physiology and immunology- the cocktail of various bacterial species or the function of the multitude of genes provided to the human organism?

Indeed, there is a high level of variability in the abundance of species, but due to a high redundancy the functional state of the whole genome pool may be very similar in very different microbial communities [24]. 


\section{Microbiota and Nutrition/Obesity}

The intestinal microbiota is not just the umbrella term of the sum of microorganisms harbored in the intestine, rather it is a highly complex group of organisms that interact with its host and actively influence its metabolism, immunologic properties and whole body physiology. Well known examples of these bacterial-derived properties are the conversion of complex nutrients as well as short chain fatty acids as a nutrient to intestinal epithelial cells, formations of a dense and highly effective defense barrier, production of essential vitamins, for instance vitamin $\mathrm{K}$, metabolism of drugs, bile salt metabolism and recirculation or the modification of nutritional compounds resulting in transformed products with potential beneficial (sometimes also hazardous) properties for the host, which is for instance the case in nutritional flavonoids.

Several years ago an alteration in the relative abundance of the two predominant bacterial phyla - Firmicutes and Bacteroidetes - was shown in obese compared to lean mice with a markedly increase of the Firmicutes to Bacteroidetes ratio of around 50\% [4]. A very similar result occurred in human studies $[25,26]$.

Furthermore, the obese phenotype appeared to be transmissible, in that the introduction of an obesity associated microbiome into the intestine of germ-free mice induced an obese phenotype [25].

A common postulation to explain these findings is an increase in the energy extraction in the metabolism of enteral food components in a Firmicutes-rich gut microbiota. In this respect, a significantly smaller energy content was found in the feces of obese mice compared with their lean counterparts [25]. 
Interestingly, the opposite procedure a transplantation of a "lean microbiota" into germ-free obese mice to induce a lean phenotype has not been performed so far.

However, the question of weight gain in relation to intestinal microbial composition is much more complex, than just a simple correlation to the ratio of the two most abundant phyla. For instance, harvesting of energy could not be correlated to the abundance and ratio of the most common phyla in a study of adolescents in a structured weight loss program [27]. Nevertheless, as mentioned below correlations with successful weight loss were seen going further down in taxonomy beyond the phylum level. Moreover, a study analyzing weight loss after metabolic surgery (gastric bypass) found a significant increase in the amount of lost kilograms in the group receiving a lactobacillus probiotic for 6 month compared to the placebo group [28]. A direct effect of the lactobacillus strains seems rather doubtful, as bacterial overgrowth simultaneously revealed to be decreased in the probiotic group, pointing rather towards a contribution of the microbial composition on the whole.

So far, it is not possible to relate or even reduce vulnerability to obesity to the abundance of a certain phyla or set of bacterial species. An interesting approach in increasing our understanding of the key elements making the difference in the obese microbiota would be a comparison of gut microbial composition from obese people with their lean relatives, aiming at the identification of a the core intestinal microbiota of each family, harboring the predisposition to obesity [29].

Intriguingly, not only a shift in microbial composition was found in a study with obese adolescents, that underwent a weight-loss program (including a low-calorie diet and structured physical activity program) - the success in losing weight revealed to be variable and dependent on the individual's microbial composition. Weight loss was substantially 
higher in individuals rich in Bacteroides fragilis, Lactobacillus, and Bifidobacterium in relation to Clostridium coccoides, despite matched dietary intake and an exercise program [27].

What is the nature of this host-microbial interaction and what are mechanisms behind a weight gain in altered microbial composition?

So far, knowledge on these mechanisms is sparse. An interesting study, already performed more than ten years ago, investigated the intestinal transcription of genes with DNA microarrays in germ-free mice that were colonized with Bacteroides thetaiotaomicron (a gram negative anaerobe) which is a highly abundant member of the Bacteroidetes in the normal microbiota in both mice and humans. Several genes, that play an important role in the intestinal absorption of lipids, were shown to be modulated by the existence of this human commensal archaeon. Furthermore, transcription of genes involved in other intestinal functions, such as xenobiotic metabolism, maturation of the intestine after birth, angiogenesis or even formation and consolidation of the mucosal barrier was also modified [30].

Additionally, an interaction of the gut microbiota and the host via hormonal mechanisms is proposed. For instance, short chain fatty acids, that are produced in a higher quantity by an "obese microbiota" may interact with G-protein receptors [31], leading to an increase in the production of proteins with important endocrine properties in mediating satiety and the regulation of energy metabolism, such as leptins or peptide YY. 
Another potential link between the intestinal microbiota and obesity may be a chronic inflammatory state, which is known to be an important component of the pathophysiology of the metabolic syndrome [32]. One potential association is via lipopolysaccharide (LPS). LPS constitutes an important part of the cell wall in gram-negative bacteria and is a wellknown very potent stimulator of an inflammatory reaction in the host, such as for instance in the systemic inflammatory response syndrome and sepsis. It has a high affinity to chylomicrons, which are formed in the digestive processing of triglycerides, rendering the chylomicrons a potential transporter of LPS from the intestinal epithelial cells in the systemic circulation [33], hereby augmenting systemic blood levels.

The alteration of the intestinal microbiota induced by a high-fat diet, in specific the decrease of Bifidobacteria, may modulate the amount of LPS, prone to enter the hosts circulation, via an Glucaogone-like peptide 2 mediated increase in intestinal barrier [34]. 


\section{Microbiota and IBD}

The gut microbiota and alterations in its complex composition are increasingly considered as a crucial factor in the pathogenesis of IBD [9,35-42], not just since the observations of an improvement in disease activity after antibiotic therapy in both CD and UC [43-45] or the absence of spontaneous colitis in germ-free mice $[9,10]$.

The dilemma of chicken and egg evidently applies to the interplay of intestinal dysbiosis and IBD and currently still is not completely solved. However, an important study investigating microbial composition in washed colonic biopsies from patients with IBD and controls, identified distinctive microbial abnormalities that correlated with disease severity, interestingly in both inflamed a non-inflamed colon specimen [42]. And further studies supporting a causal role, rather than just effect or the role of an innocent bystander, followed.

Antigen presenting cells, such as dendritic cells, are essential in microbial recognition as they are capable to sense phylogenetically highly conserved microbial-associated molecular patterns (MAMPs) via toll-like receptors (TLR) or peptidoglycan molecules from the bacterial cell walls via nucleotide-binding oligomerisation domain (NOD) like receptors (NLR).

It appears that at least some of the intestinal bacteria influence the establishment of an immune tolerogenic response through an induction of regulatory $T$ cells and IgA secretion via dendritic cells.

Furthermore, it was shown, that not only bacteria but also their metabolic products may modulate the host's immune response. For instance, polysaccharide A (PSA), produced by a Bacteroides fragilis, a human symbiontic bacteria, was shown to induce a immune- 
modulating immunologic response, providing protection from exhaustive inflammatory response induced by Helicobacter hepaticus, in that the immune response was attenuated including the production of IL-10 and suppression of pro-inflammatory cytokines [46].

Moreover, a chronic stimulation of NOD-2 in human macrophages led to a decreased proinflammatory response, evident in a decrease of TNF- $\alpha$, IL- 8 and IL- $1 \beta$, when these cells were re-stimulated after pre-treatment [47].

Accordingly, the gut microbiota and the induced tolerance of the host seem to simultaneously assure protection from invasive pathogens and also from an overreacting inflammatory response. And the disruption of this homeostatic co-existence between gut microbiota and the host including his physiologic immune tolerance is assumed to have a central role in IBD pathogenesis $[40,48]$.

In recent years a magnitude of studies looked at the composition of the commensal microbiota in IBD patients compared to healthy controls or patients with other diseases. One characteristic finding is a reduced microbial diversity in patients with IBD [39,49-51]. Further distinctive characteristics of microbial composition in patients with IBD compared to healthy controls have been described, sometimes with conflicting results, including alterations on the phylum level like a reduction of Firmicutes and Bacteroidetes and concomitant increase in the fraction of Proteobacteria and Actinobacteria [36,52,53],

Other studies identified characteristic shifts on the species level [54], such as a combination of Dialister invisus, an hitherto uncharacterized member of the Clostridiacae family, Faecalibacterium prausnitzii, Bifidobacterium adolescentis and Ruminococcus gnavus to be indicative of dysbiosis associated with CD [55]. 
Even within a specific form of IBD, differences of microbiota composition were shown according to the phenotype. For instance, in CD patients with ileal disease, disappearance of well-known commensals (Faecalibacterium and Roseburia) and an increase in Enterobacteriaceae and Ruminococcus gnavus were found [56].

However, some intestinal microbes seem to have protective effects and are therefore used as therapeutic agents in IBD, especially UC $[57,58]$. Potential mechanisms underlying this clinical benefit might be an attenuation of adherence and consecutive invasion of pathogenic intestinal E. coli strains [59] as well as positive effects of probiotic bacteria on mucosal integrity, secretion of pro-inflammatory cytokines and induction of $\beta$-defensins [6063].

Finally, the assumption that IBD may be related to a single microbial cause - hence being an infectious disease with a hitherto unidentified agent - is not a new one, but most likely was postulated as soon research on IBD pathogenesis began. Since then, a variety of candidate agents have been proposed, including mycobacteria (predominantly Mycobacterium avium paratuberculosis), Enterobacteriaceae, such as Escherichia coli strains, Listeria monocytogenes and also viral agents, such as paramyxovirus or reroviridae. However, so far no single agent has been isolated in all - or at least the vast majority of - affected patients with high consistency and results of therapeutic trials of antimicrobial agents directed at candidate pathogens have been at best inconclusive, arguing against a single microbial organism, harboring a key role in the pathogenesis of IBD. 


\section{Microbiota and Graft versus Host disease}

Another intestinal disease, where a pathogenic role of the gut microbiota is assumed is graft versus host disease (GVHD). Having in mind the common occurrence of infectious complications in GVHD, including severe life-threatening septicemia often due to gramnegative rods, a link between the gut microbiota and GVHD susceptibility has already been suggested in the 60 s and 70 s of the last century $[64,65]$

In an animal models of GVHD - syngenic GVHD (SGVHD), where lethally irradiated rodents receive a an autologous bone marrow (BM) transplantation (BMT) followed by cyclosporine A - a form of colitis develops that is not distinguishable from other murine colitis models for IBD, revealing similar microscopic findings, activation of similar phenotype of CD4+ effector T-cells and also cytokine profile [66]. Interestingly, the in vitro responsiveness of these CD4+ T-cells from these animals suffering from GVHD-related colitis showed an increase activity against bacterial antigens, which were isolated from fecal supernatant from normal animals [67].

In a recent study an increased responsiveness of $C D 4+T$ cells against microbial antigens from cecal content of normal animals was shown in a murine model. If animals were treated with a broad spectrum antibiotic combination of metronidazole and ciprofloxacin after transplantation, no clinical symptoms or characteristic pathological lesions in the intestine of cyclosporine A treated animals were observed. On an immunologic level, the previously mentioned enhanced responsiveness of CD4+ T-cells was significantly decreasing likewise, including decreased levels of various pro-inflammatory cytokines, such as IFN-y, IL-17, and TNF- $\alpha$. These findings led the authors to suggest an important pathogenic role of the intestinal microbiota in SGVHD [68]. 
Another study in mice identified the Paneth cells as a potential target in GVHD, hereby inducing a decrease in the expression and secretion of $\alpha$-defensins, which have been shown to be an important defense strategy against pathogenic bacteria. The subsequent decrease of secretion of this antimicrobial peptide induced a loss of microbial diversity, predominantly with regard to commensals, hence increasing the abundance of gram-negative bacteria, which are a well-established origin of systemic bloodstream infection.

Interestingly the degree of GVHD correlated with the degree of microbial alterations. Moreover, the use of polymyxin B, which has to potential to limit the often observed overgrowth of E. coli in GVHD, attenuated or even improved the severity of the inflammatory affection of the gut [69]. Likewise, the induced shifts towards a proinflammatory gut microbiota in another murine study of GVHD was shown to be depending on Toll-like receptor sensing (MyD88/TLR9), with a decreasing extent of intestinal pathology in TLR9-deficient mice or antagonizing therapy with a synthetic oligonucleotide inhibiting TLR9 [70]. In conclusion, these findings suggest, that - very similar to the proposed role in the pathogenesis of IBD - an induced dysbiosis represents both, a key element in the development of GVHD but also a potential target of therapeutic strategies aiming at manipulating microbial composition. 


\section{Investigating Microbial Composition in Humans Undergoing Smoking Cessation}

Smoking has emerged to be an important environmental factor influencing the course of IBD, with differing effect in UC and CD. Tobacco smoking has a protective effect in UC. The opposite is true with regard to $C D$, where smoking has detrimental influence on the future disease course. In addition, the risk of developing UC in former smoking is substantially elevated compared to never smoking [71-76] and the course of the disease is milder in former smokers who resume to smoke $[77,78]$.

Moreover, it is well known, that smokers who successfully quit smoking gain weight, to an average of about $7-8 \mathrm{~kg}$ in around $80 \%$ [79]. Although one would intuitively assume, that this weight gain is related to an increase in food intake, data addressing this issue are equivocal. For instance, a small study conducted around 25 years ago, did not detect an increase in total calory intake in the quitters who gained weight, although an increase in carbohydrate calories compared to protein calories was observed [80]. A very large $(361,662$ screened men, 12,866 randomized) population based primary prevention trial, the Multiple Risk Factor Intervention Trial (MRFIT), conducted in north America trial investigating the clinical effect on multiple cardiovascular risk factor found the following interesting results with regard to smoking cessation and weight gain: Intriguingly, successful quitters showed a reduced calory intake compared to continuing smokers or recidivist and also a generally healthier composition of their diet. Nevertheless, a weight gain was exclusively observed in men who ceased smoking, while men who continued smoking or recidivists lost body weight [81]. 
We aimed to investigate whether smoking cessation in healthy individuals leads to a change of the composition of the gut microbial composition. We therefore followed up a group of 10 smokers during smoking cessation (intervention group) over a period of 9 weeks with a prespecified complete cessation of smoking after the first week and compared these results to 10 control subjects, 5 non-smokers, and 5 continuing smokers. Stool samples were obtained 1 week before as well as 4 and 8 weeks after smoking cessation. The hitherto unpublished results revealed firstly an overall change in the microbial composition in the intervention group as indicated by analyses of TRFLPs with doubly-centered Principal Component Analyses (PCA).

Secondly, the sequences obtained by pyrosequencing showed statistically significant changes in the intervention group but not in the two control groups. Significant differences were observed on the phylum-level with increase of relative abundance of Firmicutes and Actinobacteria and decrease of Proteobacteria. In addition significant changes on the genuslevel were found, again exclusively in the intervention group. Phylogenetic diversity showed an increase in the intervention group after smoking cessation.

Our investigations show that smoking status influences the composition of the gut microbiota and that smoking cessation leads to significant changes in intestinal microbial composition. These results point to a potential pathophysiological link between smoking status and IBD and furthermore imply, that alteration of microbial composition and consecutively energy extraction by the host may play a role in weight gain after smoking cessation. 


\section{References}

1. Savage, DC. Microbial ecology of the gastrointestinal tract. Annu. Rev. Microbiol. 1977;31:107-33.

2. Turnbaugh, PJ, Ley, RE, Hamady, M, Fraser-Liggett, CM, Knight, R, Gordon, Jl. The human microbiome project. Nature 2007;449:80410.

3. Bäckhed, F, Ley, RE, Sonnenburg, JL, Peterson, DA, Gordon, Jl. Host-bacterial mutualism in the human intestine. Science 2005;307:1915-20.

4. Ley, RE, Bäckhed, F, Turnbaugh, P, Lozupone, CA, Knight, RD, Gordon, Jl. Obesity alters gut microbial ecology. Proc. Natl. Acad. Sci. U.S.A. 2005;102:11070-75.

5. Lee YK, Mazmanian SK. Has the microbiota played a critical role in the evolution of the adaptive immune system? Science 2010;330:1768-73.

6. Mazmanian, SK, Liu, CH, Tzianabos, AO, Kasper, DL. An immunomodulatory molecule of symbiotic bacteria directs maturation of the host immune system. Cell 2005;122:107-18.

7. Gill, SR, Pop, M, Deboy, RT, Eckburg, PB, Turnbaugh, PJ, Samuel, BS, Gordon, JI, Relman, DA, Fraser-Liggett, CM, Nelson, KE. Metagenomic analysis of the human distal gut microbiome. Science 2006;312:1355-59.

8. Sonnenburg, JL, Xu, J, Leip, DD, Chen, C, Westover, BP, Weatherford, J, Buhler, JD, Gordon, JI. Glycan foraging in vivo by an intestineadapted bacterial symbiont. Science 2005;307:1955-59.

9. Guarner, F, Malagelada, J. Role of bacteria in experimental colitis. Best Pract Res Clin Gastroenterol 2003;17:793-804.

10. Sellon, RK, Tonkonogy, S, Schultz, M, Dieleman, LA, Grenther, W, Balish, E, Rennick, DM, Sartor, RB. Resident enteric bacteria are necessary for development of spontaneous colitis and immune system activation in interleukin-10-deficient mice. Infect. Immun. 1998;66:5224-31.

11. Rutgeerts, P, Goboes, K, Peeters, M, Hiele, M, Penninckx, F, Aerts, R, Kerremans, R, Vantrappen, G. Effect of faecal stream diversion on recurrence of Crohn's disease in the neoterminal ileum. Lancet 1991;338:771-74.

12. Codling, C, O'Mahony, L, Shanahan, F, Quigley, EMM, Marchesi, JR. A molecular analysis of fecal and mucosal bacterial communities in irritable bowel syndrome. Dig. Dis. Sci 2010;55:392-97.

13. Kassinen, A, Krogius-Kurikka, L, Mäkivuokko, H, Rinttilä, T, Paulin, L, Corander, J, Malinen, E, Apajalahti, J, Palva, A. The fecal microbiota of irritable bowel syndrome patients differs significantly from that of healthy subjects. Gastroenterology 2007;133:24-33.

14. Backhed, F, Ding, H, Wang, T, Hooper, LV, Koh, GY, Nagy, A, Semenkovich, CF, Gordon, Jl. The gut microbiota as an environmental factor that regulates fat storage. Proc Natl Acad Sci U S A 2004;101:15718-23.

15. Vijay-Kumar, M, Aitken, JD, Carvalho, FA, Cullender, TC, Mwangi, S, Srinivasan, S, Sitaraman, SV, Knight, R, Ley, RE, Gewirtz, AT. Metabolic syndrome and altered gut microbiota in mice lacking Toll-like receptor 5. Science 2010;328:228-31.

16. Toivanen, P. Normal intestinal microbiota in the aetiopathogenesis of rheumatoid arthritis. Annals of the Rheumatic Diseases 2003;62:807-11.

17. Berer, K, Mues, M, Koutrolos, M, Rasbi, ZA, Boziki, M, Johner, C, Wekerle, H, Krishnamoorthy, G. Commensal microbiota and myelin autoantigen cooperate to trigger autoimmune demyelination. Nature 2011;479:538-41.

18. Williams, BL, Hornig, M, Parekh, T, Lipkin, WI. Application of Novel PCR-Based Methods for Detection, Quantitation, and Phylogenetic Characterization of Sutterella Species in Intestinal Biopsy Samples from Children with Autism and Gastrointestinal Disturbances. mBio 2012;3.

19. Mutlu, EA, Gillevet, PM, Rangwala, H, Sikaroodi, M, Naqvi, A, Engen, PA, Kwasny, M, Lau, CK, Keshavarzian, A. Colonic microbiome is altered in alcoholism. American Journal of Physiology - Gastrointestinal and Liver Physiology 2012.

20. Eckburg, PB, Bik, EM, Bernstein, CN, Purdom, E, Dethlefsen, L, Sargent, M, Gill, SR, Nelson, KE, Relman, DA. Diversity of the human intestinal microbial flora. Science 2005;308:1635-38.

21. Ley, RE, Hamady, M, Lozupone, C, Turnbaugh, PJ, Ramey, RR, Bircher, JS, Schlegel, ML, Tucker, TA, Schrenzel, MD, Knight, R, et al. Evolution of mammals and their gut microbes. Science 2008;320:1647-51.

22. Turnbaugh, PJ, Hamady, M, Yatsunenko, T, Cantarel, BL, Duncan, A, Ley, RE, Sogin, ML, Jones, WJ, Roe, BA, Affourtit, JP, et al. A core gut microbiome in obese and lean twins. Nature 2009;457:480-84.

23. Turnbaugh, PJ, Bäckhed, F, Fulton, L, Gordon, Jl. Diet-induced obesity is linked to marked but reversible alterations in the mouse distal gut microbiome. Cell Host Microbe 2008;3:213-23.

24. Dinsdale, EA, Edwards, RA, Hall, D, Angly, F, Breitbart, M, Brulc, JM, Furlan, M, Desnues, C, Haynes, M, Li, L, et al. Functional metagenomic profiling of nine biomes. Nature 2008;452:629-32.

25. Turnbaugh, PJ, Ley, RE, Mahowald, MA, Magrini, V, Mardis, ER, Gordon, Jl. An obesity-associated gut microbiome with increased capacity for energy harvest. Nature 2006;444:1027-31.

26. Ley, RE, Turnbaugh, PJ, Klein, S, Gordon, Jl. Microbial ecology: human gut microbes associated with obesity. Nature 2006;444:102223.

27. Santacruz, A, Marcos, A, Wärnberg, J, Martí, A, Martin-Matillas, M, Campoy, C, Moreno, LA, Veiga, O, Redondo-Figuero, C, Garagorri, $J M$, et al. Interplay between weight loss and gut microbiota composition in overweight adolescents. Obesity (Silver Spring) 2009;17:1906-15.

28. Woodard, GA, Encarnacion, B, Downey, JR, Peraza, J, Chong, K, Hernandez-Boussard, T, Morton, JM. Probiotics improve outcomes after Roux-en-Y gastric bypass surgery: a prospective randomized trial. J. Gastrointest. Surg. 2009;13:1198-204.

29. Elli, M, Colombo, O, Tagliabue, A. A common core microbiota between obese individuals and their lean relatives? Evaluation of the predisposition to obesity on the basis of the fecal microflora profile. Med. Hypotheses 2010;75:350-52.

30. Hooper, LV, Wong, MH, Thelin, A, Hansson, L, Falk, PG, Gordon, JI. Molecular analysis of commensal host-microbial relationships in the intestine. Science 2001;291:881-84.

31. Le Poul, E, Loison, C, Struyf, S, Springael, J, Lannoy, V, Decobecq, M, Brezillon, S, Dupriez, V, Vassart, G, van Damme, J, et al. Functional characterization of human receptors for short chain fatty acids and their role in polymorphonuclear cell activation. J. Biol. Chem. 2003;278:25481-89.

32. Hotamisligil, GS, Erbay, E. Nutrient sensing and inflammation in metabolic diseases. Nat. Rev. Immunol. 2008;8:923-34.

33. Ghoshal, S, Witta, J, Zhong, J, Villiers, W de, Eckhardt, E. Chylomicrons promote intestinal absorption of lipopolysaccharides. J. Lipid Res. 2009;50:90-97.

34. Cani, PD, Possemiers, S, van de Wiele, T, Guiot, Y, Everard, A, Rottier, O, Geurts, L, Naslain, D, Neyrinck, A, Lambert, DM, et al. Changes in gut microbiota control inflammation in obese mice through a mechanism involving GLP-2-driven improvement of gut permeability. Gut 2009;58:1091-103. 
35. Seksik, P, Nion-Larmurier, I, Sokol, H, Beaugerie, L, Cosnes, J. Effects of light smoking consumption on the clinical course of Crohn's disease. Inflamm. Bowel Dis. 2009;15:734-41.

36. Frank, DN, St. Amand, AL, Feldman, RA, Boedeker, EC, Harpaz, N, Pace, NR. Molecular-phylogenetic characterization of microbial community imbalances in human inflammatory bowel diseases. Proceedings of the National Academy of Sciences 2007;104:1378085.

37. Bibiloni, R, Mangold, M, Madsen, KL, Fedorak, RN, Tannock, GW. The bacteriology of biopsies differs between newly diagnosed, untreated, Crohn's disease and ulcerative colitis patients. J. Med. Microbiol. 2006;55:1141-49.

38. Lucke, K, Miehlke, S, Jacobs, E, Schuppler, M. Prevalence of Bacteroides and Prevotella spp. in ulcerative colitis. J. Med. Microbiol. 2006;55:617-24.

39. Manichanh, C. Reduced diversity of faecal microbiota in Crohn's disease revealed by a metagenomic approach. Gut 2006;55:205-11.

40. Round, JL, Mazmanian, SK. The gut microbiota shapes intestinal immune responses during health and disease. Nat. Rev. Immunol 2009;9:313-23.

41. Seksik, P, Rigottier-Gois, L, Gramet, G, Sutren, M, Pochart, P, Marteau, P, Jian, R, Doré, J. Alterations of the dominant faecal bacterial groups in patients with Crohn's disease of the colon. Gut 2003;52:237-42.

42. Swidsinski, A, Ladhoff, A, Pernthaler, A, Swidsinski, S, Loening-Baucke, V, Ortner, M, Weber, J, Hoffmann, U, Schreiber, S, Dietel, M, et al. Mucosal flora in inflammatory bowel disease. Gastroenterology 2002;122:44-54.

43. Prantera, C, Lochs, H, Grimaldi, M, Danese, S, Scribano, ML, Gionchetti, P. Rifaximin-extended intestinal release induces remission in patients with moderately active Crohn's disease. Gastroenterology 2012;142:473-481.e4.

44. Khan, KJ, Ullman, TA, Ford, AC, Abreu, MT, Abadir, A, Abadir, A, Marshall, JK, Talley, NJ, Moayyedi, P. Antibiotic therapy in inflammatory bowel disease: a systematic review and meta-analysis. Am. J. Gastroenterol 2011;106:661-73.

45. Ohkusa, T, Kato, K, Terao, S, Chiba, T, Mabe, K, Murakami, K, Mizokami, Y, Sugiyama, T, Yanaka, A, Takeuchi, Y, et al. Newly Developed Antibiotic Combination Therapy for Ulcerative Colitis: A Double-Blind Placebo-Controlled Multicenter Trial. Am J Gastroenterol 2010;105:1820-29.

46. Mazmanian, SK, Round, JL, Kasper, DL. A microbial symbiosis factor prevents intestinal inflammatory disease. Nature 2008;453:62025.

47. Hedl, M, Li, J, Cho, JH, Abraham, C. Chronic stimulation of Nod2 mediates tolerance to bacterial products. Proc. Natl. Acad. Sci. U.S.A. 2007;104:19440-45.

48. Abraham, C, Cho, JH. Inflammatory bowel disease. N. Engl. J. Med. 2009;361:2066-78.

49. Sokol, H, Lay, C, Seksik, P, Tannock, GW. Analysis of bacterial bowel communities of IBD patients: what has it revealed? Inflamm. Bowel Dis. 2008;14:858-67.

50. Martinez, C, Antolin, M, Santos, J, Torrejon, A, Casellas, F, Borruel, N, Guarner, F, Malagelada, J. Unstable Composition of the Fecal Microbiota in Ulcerative Colitis During Clinical Remission. Am J Gastroenterol 2008;103:643-48.

51. Ott, SJ, Musfeldt, M, Wenderoth, DF, Hampe, J, Brant, O, Fölsch, UR, Timmis, KN, Schreiber, S. Reduction in diversity of the colonic mucosa associated bacterial microflora in patients with active inflammatory bowel disease. Gut 2004;53:685-93.

52. Kang, S, Denman, SE, Morrison, M, Yu, Z, Dore, J, Leclerc, M, McSweeney, CS. Dysbiosis of fecal microbiota in Crohn's disease patients as revealed by a custom phylogenetic microarray. Inflamm Bowel Dis 2010;16:2034-42.

53. Mukhopadhya, I, Hansen, R, El-Omar, EM, Hold, GL. IBD[mdash]what role do Proteobacteria play? Nat Rev Gastroenterol Hepatol 2012;9:219-30.

54. Mondot, S, Kang, S, Furet, JP, Aguirre Carcer, D de, McSweeney, C, Morrison, M, Marteau, P, Doré, J, Leclerc, M. Highlighting new phylogenetic specificities of Crohn's disease microbiota. Inflamm Bowel Dis 2011;17:185-92.

55. Joossens, M, Huys, G, Cnockaert, M, Preter, V de, Verbeke, K, Rutgeerts, P, Vandamme, P, Vermeire, S. Dysbiosis of the faecal microbiota in patients with Crohn's disease and their unaffected relatives. Gut 2011;60:631-37.

56. Willing, BP, Dicksved, J, Halfvarson, J, Andersson, AF, Lucio, M, Zheng, Z, Järnerot, G, Tysk, C, Jansson, JK, Engstrand, L. A Pyrosequencing Study in Twins Shows That Gastrointestinal Microbial Profiles Vary With Inflammatory Bowel Disease Phenotypes. Gastroenterology 2010;139:1844-1854.e1.

57. Fedorak, RN, Dieleman, LA. Probiotics in the treatment of human inflammatory bowel diseases: update 2008. J. Clin. Gastroenterol. 2008;42 Suppl 2:S97-103.

58. Kruis, W, Fric, P, Pokrotnieks, J, Lukás, M, Fixa, B, Kascák, M, Kamm, MA, Weismueller, J, Beglinger, C, Stolte, M, et al. Maintaining remission of ulcerative colitis with the probiotic Escherichia coli Nissle 1917 is as effective as with standard mesalazine. Gut 2004;53:1617-23.

59. Boudeau, J, Glasser, A, Julien, S, Colombel, J, Darfeuille-Michaud, A. Inhibitory effect of probiotic Escherichia coli strain Nissle 1917 on adhesion to and invasion of intestinal epithelial cells by adherent-invasive E. coli strains isolated from patients with Crohn's disease. Aliment. Pharmacol. Ther. 2003;18:45-56.

60. Ukena, SN, Singh, A, Dringenberg, U, Engelhardt, R, Seidler, U, Hansen, W, Bleich, A, Bruder, D, Franzke, A, Rogler, G, et al. Probiotic Escherichia coli Nissle 1917 inhibits leaky gut by enhancing mucosal integrity. PLoS ONE 2007;2:e1308.

61. Peran, L, Camuesco, D, Comalada, M, Nieto, A, Concha, A, Adrio, JL, Olivares, M, Xaus, J, Zarzuelo, A, Galvez, J. Lactobacillus fermentum, a probiotic capable to release glutathione, prevents colonic inflammation in the TNBS model of rat colitis. Int J Colorecta Dis 2006;21:737-46.

62. Fitzpatrick, LR, Small, J, Hoerr, RA, Bostwick, EF, Maines, L, Koltun, WA. In vitro and in vivo effects of the probiotic Escherichia col strain M-17: immunomodulation and attenuation of murine colitis. Br. J. Nutr. 2008;100:530-41.

63. Möndel, M, Schroeder, BO, Zimmermann, K, Huber, H, Nuding, S, Beisner, J, Fellermann, K, Stange, EF, Wehkamp, J. Probiotic E. coli treatment mediates antimicrobial human beta-defensin synthesis and fecal excretion in humans. Mucosal immunology 2009;2:16672.

64. van Bekkum, DW, Roodenburg, J, Heidt, PJ, van der Waaij, D. Mitigation of secondary disease of allogeneic mouse radiation chimeras by modification of the intestinal microflora. J. Natl. Cancer Inst. 1974;52:401-04.

65. van BEKKUM, D, VOS, O. Treatment of secondary disease in radiation chimaeras. Int. J. Radiat. Biol. 1961;3:173-81.

66. Strober, W, Fuss, IJ, Blumberg, RS. The immunology of mucosal models of inflammation. Annu. Rev. Immunol. 2002;20:495-549.

67. Cong, Y, Brandwein, SL, McCabe, RP, Lazenby, A, Birkenmeier, EH, Sundberg, JP, Elson, CO. CD4+ T cells reactive to enteric bacterial antigens in spontaneously colitic $\mathrm{C} 3 \mathrm{H} / \mathrm{HeJBir}$ mice: increased T helper cell type 1 response and ability to transfer disease. J. Exp. Med. 1998;187:855-64.

68. Brandon, JA, Jennings, CD, Kaplan, AM, Bryson, JS. Murine Syngeneic Graft-Versus-Host Disease Is Responsive to Broad-Spectrum Antibiotic Therapy. The Journal of Immunology 2011;186:3726-34. 
69. Eriguchi, Y, Takashima, S, Oka, H, Shimoji, S, Nakamura, K, Uryu, H, Shimoda, S, Iwasaki, H, Shimono, N, Ayabe, T, et al. Graft-versushost disease disrupts intestinal microbial ecology by inhibiting Paneth cell production of $\alpha$-defensins. Blood 2012.

70. Heimesaat, MM, Nogai, A, Bereswill, S, Plickert, R, Fischer, A, Loddenkemper, C, Steinhoff, U, Tchaptchet, S, Thiel, E, Freudenberg, MA, et al. MyD88/TLR9 mediated immunopathology and gut microbiota dynamics in a novel murine model of intestinal graft-versushost disease. Gut 2010;59:1079-87.

71. Mahid, SS, Minor, KS, Soto, RE, Hornung, CA, Galandiuk, S. Smoking and inflammatory bowel disease: a meta-analysis. Mayo Clin. Proc. 2006;81:1462-71.

72. Cosnes, J, Carbonnel, F, Beaugerie, L, Le Quintrec, Y, Gendre, JP. Effects of cigarette smoking on the long-term course of Crohn's disease. Gastroenterology 1996;110:424-31.

73. Höie, O, Wolters, F, Riis, L, Aamodt, G, Solberg, C, Bernklev, T, Odes, S, Mouzas, IA, Beltrami, M, Langholz, E, et al. Ulcerative colitis: patient characteristics may predict 10-yr disease recurrence in a European-wide population-based cohort. Am. J. Gastroenterol. 2007;102:1692-701.

74. Kane, SV, Flicker, M, Katz-Nelson, F. Tobacco use is associated with accelerated clinical recurrence of Crohn's disease after surgically induced remission. J. Clin. Gastroenterol. 2005;39:32-35.

75. Breuer-Katschinski, BD, HollÃß口nder, N, Goebell, H. Effect of cigarette smoking on the course of Crohn's disease. Eur J Gastroenterol Hepatol 1996;8:225-28.

76. Beaugerie, L, Massot, N, Carbonnel, F, Cattan, S, Gendre, JP, Cosnes, J. Impact of cessation of smoking on the course of ulcerative colitis. Am. J. Gastroenterol. 2001;96:2113-16.

77. Birrenbach, T, Böcker, U. Inflammatory bowel disease and smoking: a review of epidemiology, pathophysiology, and therapeutic implications. Inflamm. Bowel Dis. 2004;10:848-59.

78. Rudra, T, Motley, R, Rhodes, J. Does smoking improve colitis? Scand. J. Gastroenterol. Suppl. 1989;170:61-3; discussion 66-8.

79. O'Hara, P, Connett, JE, Lee, WW, Nides, M, Murray, R, Wise, R. Early and late weight gain following smoking cessation in the Lung Health Study. Am. J. Epidemiol 1998;148:821-30.

80. Rodin, J. Weight change following smoking cessation: the role of food intake and exercise. Addict Behav 1987;12:303-17.

81. Stamler, J, Rains-Clearman, D, Lenz-Litzow, K, Tillotson, JL, Grandits, GA. Relation of smoking at baseline and during trial years 1-6 to food and nutrient intakes and weight in the special intervention and usual care groups in the Multiple Risk Factor Intervention Trial. Am. J. Clin. Nutr 1997;65:374S-402S 